\title{
Improved Grid Connected PV System based on SVPWM Inverter and using P-V Optimal Slope MPPT Technique
}

\author{
Tarek Oukhoya \\ Analyse et commande des \\ systèmes d'énergie électrique \\ (ACSEE) - LISER \\ ENSEM, Université Hassan II \\ Casablanca, Morocco
}

\author{
Abdelhalim Sandali \\ Analyse et commande des \\ systèmes d'énergie électrique \\ (ACSEE) - LISER \\ ENSEM, Université Hassan II \\ Casablanca, Morocco
}

\author{
Ahmed Cheriti \\ Research Group in Industrial \\ Electronics Department of \\ Electrical and Computer \\ Engineering \\ Université du Québec à Trois- \\ Rivières, Canada
}

\begin{abstract}
This work proposes a Grid-Connected Photovoltaic Generation System (PV-GCGS) with a new and simple Maximum Power Point Tracking (MPPT). The system is composed of two stages: the short circuit current sensor stage and the dc-ac conversion stage that is a three phase Voltage Source Inverter (VSI) with space vector modulation (SVPWM) technique. The adopted MPPT technique calculates the phase angle between the inverter voltage and grid voltage to determine the optimal slope of the power load line which corresponds to the Maximum Power Point (MPP) of PV generator. The whole components of the adopted PVGCGS (Cdc conductance, Lf leakage inductance of transformer, transformer ratio and SVPWM characteristics) are designed to meet the constraints of performance and grid integration. A closed-loop controller is proposed to regulate the inverter voltage amplitude to be equal to the grid voltage in order to minimize the reactive power consumed by the transformer leakage reactance. The results are validated by simulation in the Matlab-Simulink environment.
\end{abstract}

\section{Keywords}

MPPT, short circuit-current, Grid-Connected Photovoltaic Generation System, reactive power, harmonic analysis

\section{INTRODUCTION}

In recent years, power generation from solar PV has known a rapid growth. It expanded by $50 \%$ per year worldwide over the last decade, reaching almost $100 \mathrm{TWh}$ in 2012 [1]. Even though the deployment of photovoltaic systems has been increasing steadily for the last 20 years, solar technologies still suffer from some drawbacks that make them poorly competitive on an energy market dominated by fossil fuels: high capital cost, modest conversion efficiency, and intermittency. From a scientific and technical viewpoint, the development of new technologies with higher conversion efficiencies and low production costs is a key requirement for enabling the deployment of solar energy at a large scale [2]. To improve competitiveness of the PV generation, several research works have been made either to improve the efficiency of PV panels either to improve the power electronics interface. In the field of power electronics, two aspects are considered to improve competitiveness. In the first aspect, several MPPT algorithms are developed to maximize the output power from PV array [3-4]. In the second aspect, the use of PWM inverters and filters make it possible to improve quality of the energy injected into the grid [5-6].
These two aspects are related between them. Therefore to have a better competitiveness, these both aspects must be taken into consideration. The goals are: $i$ ) the proposal of grid connected PV system which uses a P-V optimal slope MPPT technique $i$ i) the design of the whole PV-GCGS components to meet the constraints of efficiency and power quality.

This paper is organized as follows. In section 2, we briefly describe classical MPPT techniques. Section 3 presents and discuses the proposed system and its MPPT. Modeling and design of the adopted PV-GCGS are presented in sections 4 and 5. Simulation results are given in section 6. Finally, Section 7 outlines the conclusion.

\section{CLASSICAL MPPT TECHNIQUES}

\subsection{Perturbation and Observation (P\&O)}

This technique reaches the maximum power point of PV panels using repeating sequences of perturbing, observing and comparing the power generated by the PV panels. It is widely used in PV systems because of its simplicity and easy implementation. However, it presents drawbacks such as slow response speed, oscillation around the MPP in steady state, and even tracking in wrong way under rapidly changing atmospheric conditions.

\subsection{Incremental Conductance}

This technique is also widely applied in the MPPT controllers. It is based on comparing the incremental conductance to the instantaneous conductance of the PV panels. The maximum PV power output can be reached when these two quantities are equal. The main advantage of this algorithm over the $\mathrm{P} \& \mathrm{O}$ method is its rapidity to track the maximum power point of the PV panels.

\subsection{Fractional Open-Circuit Voltage}

This technique is based on the approximate linear relationship between the MPP voltage $\left(V_{M P P}\right)$ and the open circuit voltage $\left(V_{O C}\right)$, which varies with the irradiance and temperature [7]. The $\mathrm{V}_{\mathrm{MPP}}$ is calculated after measuring the open-circuit voltage of the PV panels by the following relationship:

$$
V_{M P P} \approx M_{v} * V_{O C}
$$

Where $M v$ is a constant of proportionality, it depends on the characteristics of the PV panels used and environmental data (temperature and irradiation). According to [7] the constant $M v$ is between 0.71 and 0.78 . 


\subsection{Fractional Short-Circuit Current}

The same reasoning as fractional open circuit but this time is applied to the current. Current corresponding to the MPP is deduced from the measurement of the short-circuit current $\left(I_{S C}\right)$ by the following approximate linear relationship:

$I_{M P P} \approx M_{C} * I_{S C}$

The proportional parameter $M c$ is approximately equal to 0.92 [8].

\section{PROPOSED PV SYSTEM}

\subsection{Architecture of the proposed PV system}

The proposed technique is based on the determination of the optimal slope of the power load line which corresponds to the MPP of PV generator. It requires only the measurement of the short-circuit current of the PV generator and it reaches the MPP of the PV generator with the first test and without iteration by adjusting the phase angle between the inverter voltage and grid voltage. The considered PV system (fig.1) is composed of the following stages: PV generator, short-circuit current sensor of PV generator, SVPWM inverter, and matching transformer. Amplitude modulation index and frequency modulation index of SVPWM inverter are noted $m a$ and $m f$. Transformer ratio is noted $m$. We kept the transformer for its advantage to eliminate the leakage current, to filter the injected currents in the grid (One contribution of this work) and to adjust voltage levels. The size of the transformer is compensated by the lack of filtering inductances, because the transformer's leakage inductances are used for filtering the currents injected into the grid.

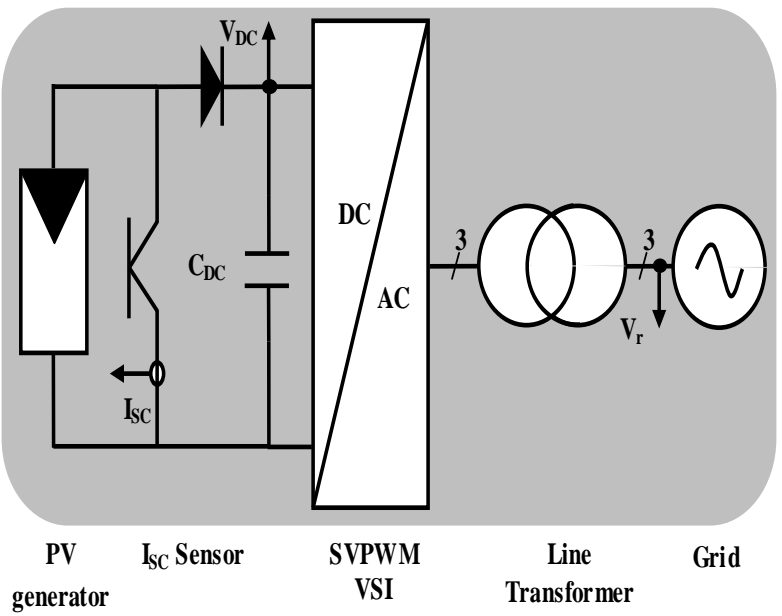

Fig 1: Proposed PV Grid-Connected Generation System

\subsection{Proposed MPPT technique}

Inverter-grid link can be modeled by the single line diagram shown on fig. 2. Power-voltage characteristic of the load, i.e. grid connected inverter, is then a line whose expression is:

$$
P_{\text {load }}=\frac{3}{4} \frac{m_{a} \cdot m \cdot V_{u t}}{X} \cdot \sin \theta \cdot V_{P V}
$$

Where:

- $V_{u t}$ : Magnitude of line to line voltage grid.

- $V_{P V}:$ PV generator voltage.

- $X=2 \pi . F . L:$ Transformer's leakage reactance.
- $\quad F$ : Grid's frequency.

- $\quad \theta$ : the phase angle between the inverter voltage and grid voltage.

The slope of this characteristic is:

$S_{\text {sys }}=\frac{3}{4} \frac{m_{a} \cdot m \cdot V_{u t}}{X} \cdot \sin \theta$

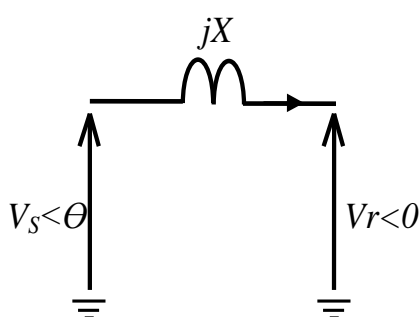

a) Single line diagram

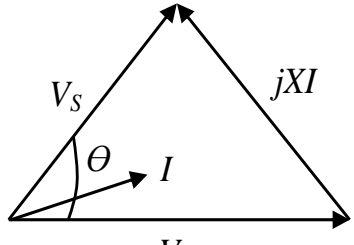

$\mathrm{Vr}$

b) Vector diagram
Fig 2: Inverter-Grid link Model.

Fig.3 shows the V-I and V-P curves of PV generator. In the V-P plan, the MPP is the intersection of the P-V curve of the $\mathrm{PV}$ generator and the load line (inverter- grid) having an optimal slope:

$$
S_{o p}=\frac{P_{M P P}}{V_{M P P}}=\frac{M_{C} I_{C C} \cdot M_{v} V_{C O}}{M_{v} V_{C O}}
$$

To extract the maximum power from the PV generator, it is necessary that the load line slope is equal to the optimal slope. Thus:

$$
\frac{3}{4} \frac{m_{a} \cdot m \cdot V_{u t}}{X} \cdot \sin \theta=M_{C} I_{C C}
$$

Therefore the optimal slope can be achieved by controlling $m a, m$ and $\theta$. This approach was already presented in [9]. In [10], $\theta$ is used to determine the optimal slope and the other parameters are taken constants, and calculated to satisfy the requirements of quality and grid connection. In this work $m a$ is also controlled in order to achieve the optimal slope and to satisfy the requirements of quality and grid connection. A SVPWM is used to meet all these requirements.

To extract the maximum power from the PV generator, the fundamental voltage generated by the VSI based on SVPWM control is phase shifted to the mains voltage by:

$$
\theta=\operatorname{asin}\left(\frac{3}{4} \frac{X}{m_{a} \cdot m \cdot V_{u t}} \cdot M_{c} \cdot I_{S C}\right)
$$

This MPPT technique requires the measurement of shortcircuit current and the estimate of current factor $(M c)$.

\subsection{I $_{\text {sc }}$ sensor stage}

This stage is used to measure the short-circuit current of the PV generator and operates in more favorable conditions than in the case of the boost in conventional systems. Indeed, the frequency of the power switches of this stage is less than $50 \mathrm{~Hz}$ in the proposed system while it exceeds $20 \mathrm{KHz}$ in the conventional systems. Also, this stage saves the inductance of boost. Consequently, the benefits of this stage are reducing losses due to the switching of the power switches (low switching frequency), minimizing size and cost.

\subsection{Current proportional parameter estimation}

The effectiveness of the proposed MPPT depends on the value 
assigned to $M c$ particularly its dependence on climatic conditions. In [8], Mc is estimated under various conditions of temperature, illumination and for different PV panels. This reference indicates that the current factor is always constant, even if the temperature and illumination varies.

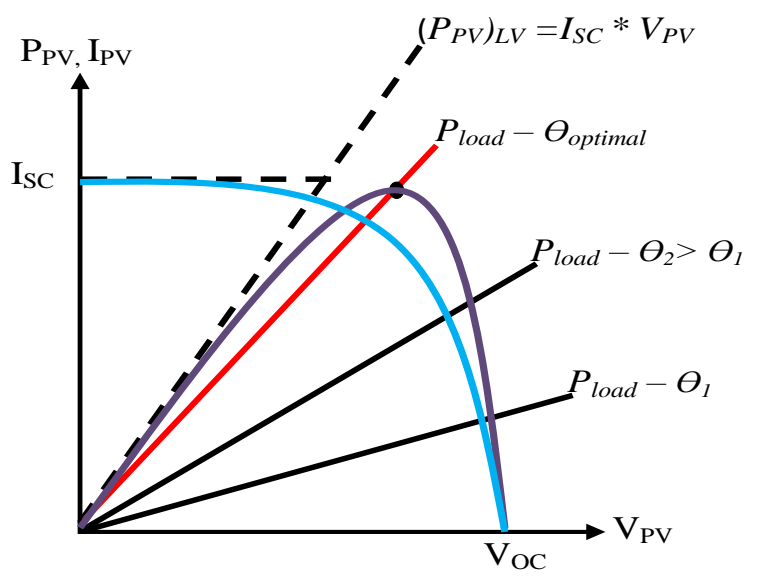

Fig 3: P-V characteristics of PV generator and grid connected inverter

In this paper, a series of simulations of a PV generator composed $4 \mathrm{PV}$ panels in series is performed. The simulation results of this generator are shown in fig.4. These results confirm those of [8]. The variation of $M c$ is slightly low and its impact on the accuracy of the algorithm is very limited. Therefore, $M c$ is taken as a constant and it is assigned to the value given in the data sheet.

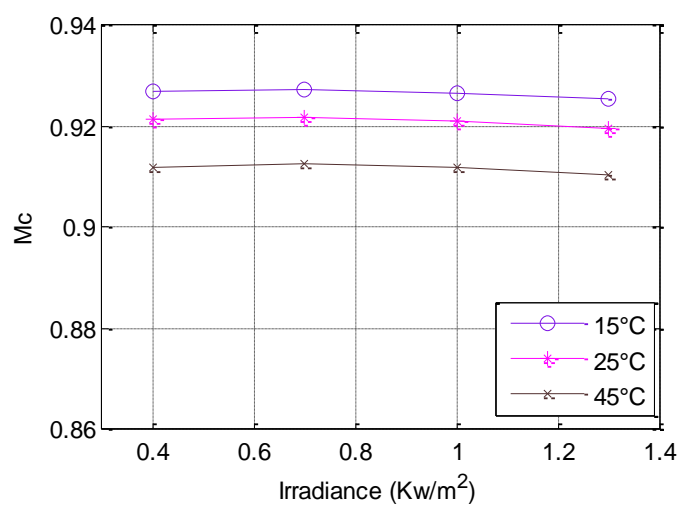

Fig 4: Current factor vs climatic data

\section{MODELING OF PV SYSTEM PROPOSED}

\subsection{Flow of reactive power}

The expression of active power (3) and reactive power consumed by the transformer leakage reactance (8) are established from the model of the inverter-grid link fig. 2 .

$$
Q_{L}=3 X I^{2}=\frac{3 \cdot\left(V_{s}{ }^{2}+V_{r}{ }^{2}-2 V_{s} V_{r} \cos (\theta)\right)}{X}
$$

According to (3) and (8) $\frac{Q_{L}}{P_{s y s}}$ can be obtained as:

$$
\frac{Q_{L}}{P_{s y s}}=\frac{1+\left(V_{r} / V_{S}\right)^{2}-2 \cdot\left(V_{r} / V_{S}\right) \cdot \cos \theta}{\left(V_{r} / V_{S}\right) \cdot \sin \theta}
$$

Fig.5 shows $(Q L / P)$ vs $(V r / V s)$ for different values of $\theta$.

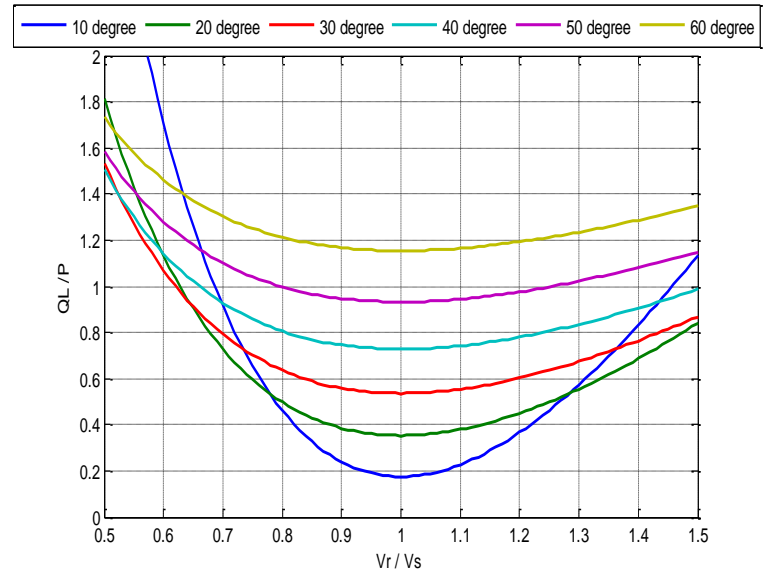

Fig 5: Reactive power consumed by the grid inverter link

The power factors on both sides (generator and receiver) are defined as follows:

$$
\begin{aligned}
& P F_{r}=\sin (\theta) / \sqrt{1+\left(\frac{V_{r}}{V_{s}}\right)^{2}-2\left(\frac{V_{r}}{V_{s}}\right) \cos (\theta)} \\
& P F_{S}=\sin (\theta) / \sqrt{1+\left(\frac{V_{s}}{V_{r}}\right)^{2}-2\left(\frac{V_{s}}{V_{r}}\right) \cos (\theta)}
\end{aligned}
$$

Fig.6 shows the $P F$ curves vs $\theta$ for different values of $(V s / V r)$.

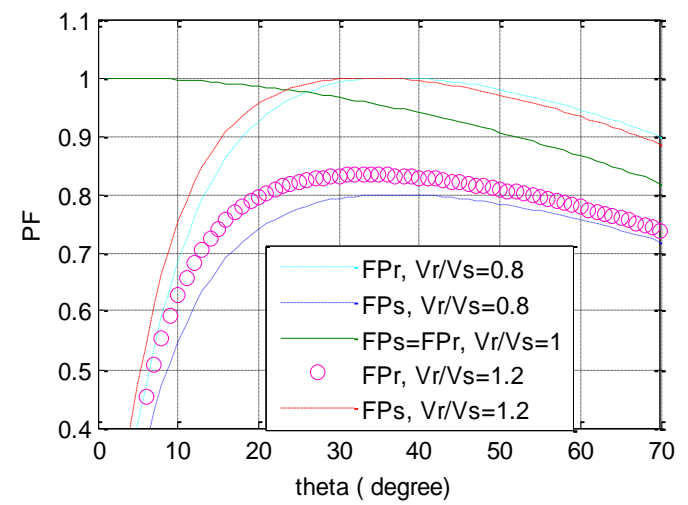

Fig 6: Sending (Inverter) and receiving (Grid) power factors

\subsection{Quality of currents injected into the grid}

The quality of the currents generated by the inverter is quantified by $T H D I$, it depends on the voltage $T H D(T H D V)$. Conditioning and filtering are controlled by $m a, m f$ and $L$. The lower voltage value is obtained when: $m a=1,15$ to calculate $T H D I$, it is necessary to determine the harmonic voltage, and then deduce current harmonics. Harmonics are divided into packets centered around multiples of $m f . F$ ( $F$ is the fundamental frequency).From [11-12], the voltage and current harmonics (ih) are calculated for the first 200 packets. Knowing that the fundamental current is:

$i_{1}=2 \cdot \sin (\theta / 2)$ p.u

The THDI of 200 packets becomes: 
$T H D I=\frac{\sqrt{\sum i_{h}^{2}}}{2 \cdot \sin (\theta / 2)}=\frac{I H(m f)}{2 \cdot \sin (\theta / 2)}$

$I H(m f)$ represents the amplitude of the total harmonic currents of the first 200 packets in $p . u$ (voltage reference is $V_{P V} / 2$ and current reference is $\left(V_{P V} / 2\right) / X$. Fig 7.a and 7.b show $I H$ vs $m f$ and THDI vs $\theta$ respectively.

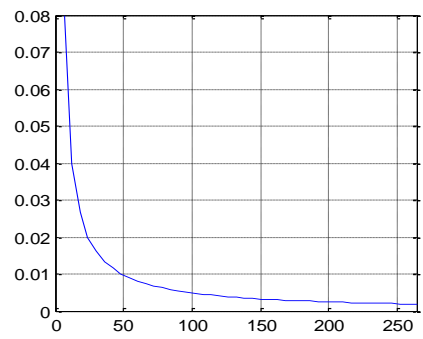

a) IH vs $m f$

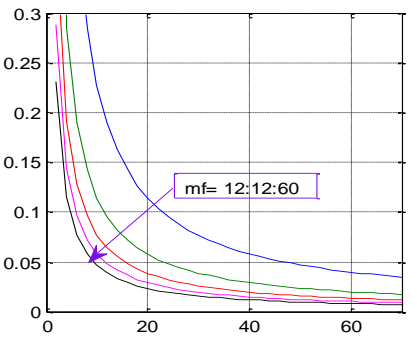

b) THDI vs theta
Fig 7: Quality of the currents generated by the inverter

\section{PV SYSTEM DESIGN}

The purpose of this section is to determine the parameters of all components of the proposed PV system to meet the following specifications:

- $\quad$ Power: $P_{\min } \leq P_{\text {sys }} \leq P_{\max }$

- Power factor: $P F_{r} \geq F P_{\text {min }}$

- Power quality: $T H D I \leq T H D I_{\max }$

- Best performance, cost and size are possible.

\subsection{Voltage control loop}

From fig. 5 the reactive power consumed by the transformer leakage reactance is minimal when:

$$
V_{s} / V_{r}=1
$$

Knowing that: $V_{s}=m_{a} \cdot \frac{V_{m p p}}{2}$ and Vmpp varies according to the climatic conditions (illumination and temperature), $m a$ should be controlled to keep $V s$ equal to $V r$ (grid voltage).

Fig. 8 shows the block diagram of voltage controller

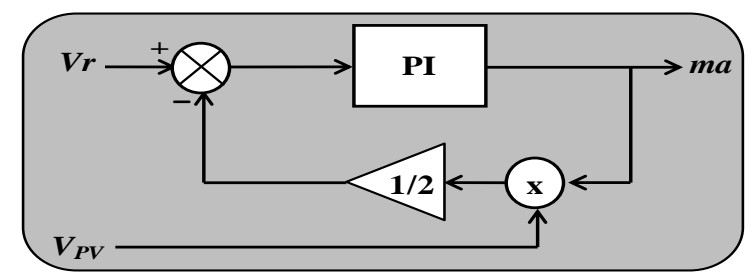

Fig 8: Block diagram of voltage controller

The transfer function of the PI controller is expressed as:

$$
C(s)=k_{p}+\frac{k_{i}}{s}
$$

Where $k p$ and $k i$ are the proportional and integral gains, respectively.

The transfer function of the closed loop control system (fig.8) is expressed as:

$$
T(s)=\frac{k_{p}+\frac{k_{i}}{s}}{1+k \cdot\left(k_{p}+\frac{k_{i}}{s}\right)}=\frac{\frac{k_{p}}{1+k \cdot k_{p}} s+\frac{k_{i}}{1+k \cdot k_{p}}}{s+\frac{k \cdot k_{i}}{1+k \cdot k_{p}}}
$$

Where $k$ is equal to $V m p p / 2$. As the value of $k p$ increases, the pole of the transfer function $T(s)(17)$ approaches the origin of s-plane, which is not desirable. Therefore, to eliminate the transient behavior of a first-order system, $k p$ should be chosen to be small [13]. Thus, $k p$ and $k i$ can be written as:

$$
k_{p} \approx 0 \text { and } k_{i} \cdot k=\frac{1}{\tau}
$$

Substituting $k p$ and $k . k i$ of (18) in (17), the transfer function becomes:

$$
T(s)=\frac{\frac{1}{k}}{1+\tau s}
$$

$\tau$ : is chosen in the range of $0.5-5 \mathrm{~ms}$ to get a fast and accurate response.

\subsection{Choice of ma and $\mathrm{m}$}

The MPP voltage varies according to the climatic conditions (illumination and temperature) variation. So to calculate the transformer ratio an interval of MPP voltage variation is chosen:

$$
V_{P V \min } \leq V_{M P P} \leq V_{P V \max }
$$

To satisfy (15), taking into account (20), $m a$ should be a variable. The range variation of $m a$ is:

$$
m_{\text {amin }} \leq m_{a} \leq m_{\text {amax }}
$$

Knowing that: $V_{s}=m_{a} \cdot \frac{V_{m p p}}{2}$ and $V_{r}=m \cdot V_{u t}$ (constant) and considering (21) the $V_{M P P}$ range can be expressed as:

$$
\frac{2 . V_{r}}{m_{\text {amax }}} \leq V_{M P P} \leq \frac{2 . V_{r}}{m_{\text {amin }}}
$$

$V r$ is the transformer secondary voltage, it is constant. So from (20) and (22) the following expression is deduced:

$$
V_{P V \min } \cdot m_{\text {amax }}=V_{P V \max } \cdot m_{\text {amin }}
$$

Therefore the transformer ratio is given by:

$$
m=\frac{V_{P V \min } \cdot m_{a \max }}{2 \cdot V_{u t}}=\frac{V_{P V \max } \cdot m_{a \min }}{2 \cdot V_{u t}}
$$

\subsection{Interval choice of $X$}

Taking into account (10) and to meet the power factor specification the following condition should be fulfilled:

$$
\theta \leq \theta_{\max }
$$

So for (25) remains satisfied, it is necessary that the following expression must be fulfilled when the system operates at maximum power $P_{\max }$, and taking into account (15):

$$
\frac{3}{2}\left(m_{a} \frac{V_{P V}}{2}\right)^{2} \frac{\sin \left(\theta_{\max }\right)}{X} \geq P_{\max }
$$

So:

$$
X \leq X_{\max }=\frac{3}{2}\left(m_{a} \frac{V_{P V}}{2}\right)^{2} \frac{\sin \left(\theta_{\max }\right)}{P_{\max }}
$$

Initially $m f$ is chosen arbitrarily and the corresponding $I H$ is determined from the curve in fig.7a.

To meet the THDI specification and substituting (13) into (14) yields:

$$
\sin (\theta / 2) \geq \frac{1}{2} \frac{I H(m f)}{T H D I_{\max }}
$$

So it is necessary to set a minimum value of $\theta$ : 


$$
\theta \geq \theta_{\min }=2 \cdot \operatorname{asin}\left(\frac{1}{2} \frac{I H(m f)}{T H D I_{\max }}\right)
$$

For (29) remains satisfied, it is necessary that the following expression must be fulfilled when the system operates at minimum power $P_{\text {min }}$, and taking into account (15):

$$
\frac{3}{2}\left(m_{a} \frac{V_{P V}}{2}\right)^{2} \frac{\sin \left(\theta_{\min }\right)}{X} \leq P_{\min }
$$

Substituting (29) into (30) yields:

$X \geq X_{\min }=\frac{3}{8} \frac{\left(m_{a} \cdot V_{P V}\right)^{2}}{P_{\min }} \sin \left(2 \cdot \operatorname{asin}\left(\frac{1}{2} \frac{I H(m f)}{T H D I_{\max }}\right)\right)$

If $X_{\min } \geq X_{\max }$ or the choice interval of the transformer's leakage reactance is not sufficiently large, then it is necessary to adjust the value of $m f$.

Therefore the transformer's leakage reactance should meet:

$$
X_{\min }<X_{t r}<X_{\max }
$$

\subsection{Determination $\mathbf{C}_{\mathrm{dc}}$}

Measuring the $I_{S C}$ should not cause a large distortion of the DC voltage supply. The value of $C_{d c}$ is calculated to limit the voltage drop during the operation of the $I_{S C}$ sensor.

For the capacitor can replace the PV generator during the short-circuit without that the relative variation of its voltage exceeds $(V P V / \triangle V P V)_{\max }$, it is necessary that:

$$
C_{d c} \geq \frac{P_{P V} \cdot \Delta t_{S C}}{V_{P V}^{2}} \frac{1}{\left(\Delta V_{P V} / V_{P V}\right)}
$$

$\Delta t_{S C}$ should be sufficient for the current to be stabilized. It is determined by a return on experience $\Delta t_{S C}=25 \mu \mathrm{s}$

\subsection{Numerical computation}

The PV generator consists of four panels in series (ETP636135).

\section{Table 1: Parameters and specifications of the proposed PV} system

\begin{tabular}{lc}
\hline \hline Parameter & Value \\
\hline Maximum power $\left(P_{M P P}\right)$ & $135 \mathrm{~W}$ \\
Voltage @ $\mathrm{P}_{\mathrm{MPP}}\left(V_{M P P}\right)$ & $17.67 \mathrm{~V}$ \\
Current @ $\mathrm{P}_{\mathrm{MPP}}\left(I_{M P P}\right)$ & $7.67 \mathrm{~A}$ \\
Short circuit current $\left(I_{S C}\right)$ & $8.41 \mathrm{~A}$ \\
$V_{u t}$ and $F$ & $220 \mathrm{~V}-50 \mathrm{~Hz}$ \\
$P_{\max }$ & $600 \mathrm{~W}$ \\
$P_{\min }$ & $60 \mathrm{~W}$ \\
$V_{P V \max }$ & $73 \mathrm{~V}$ \\
$T H D I_{\max }$ & $5 \%$ \\
$\Delta t_{S C}$ & $25 \mu \mathrm{s}$ \\
\hline \hline
\end{tabular}

The flowchart of fig.9 summarizes the procedure for choosing the suitable transformer to be used to connect the PV generator-inverter to the grid.

According to the data tabl.1 and the flowchart fig.9. The calculation results are given below:

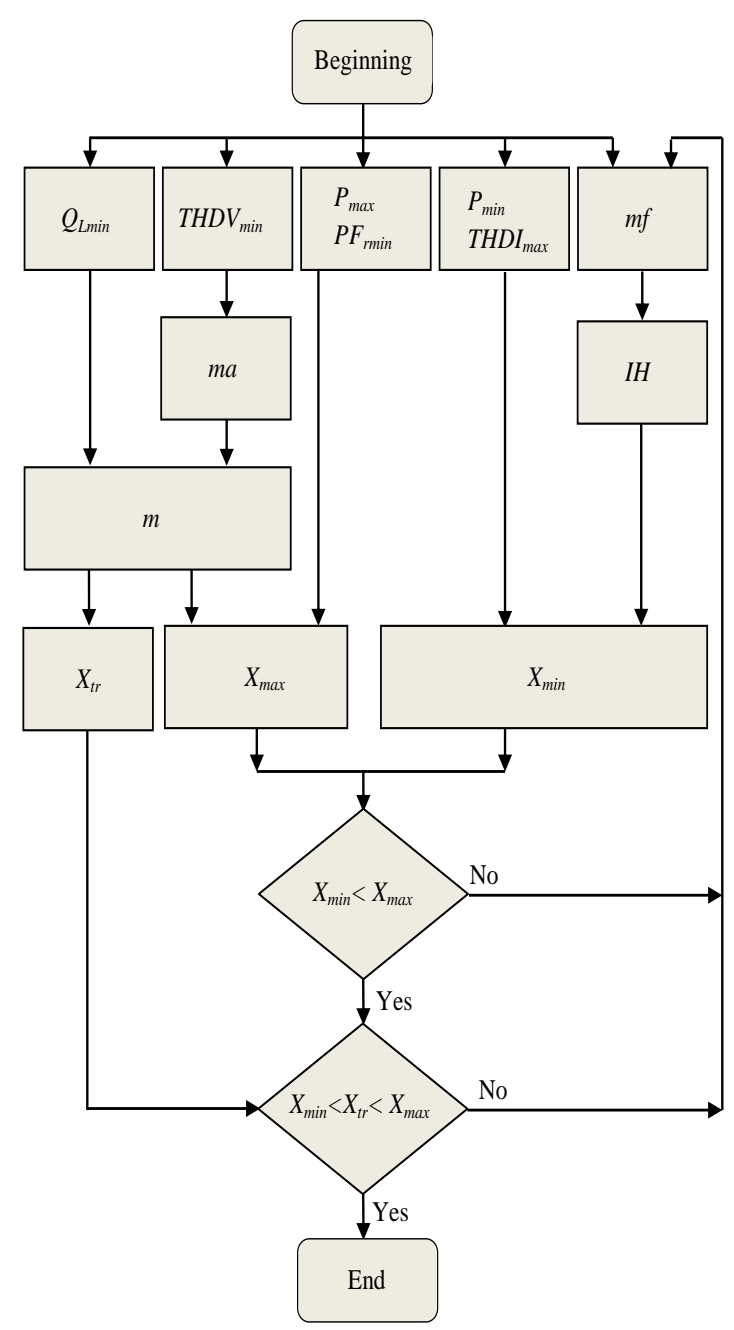

Fig 9: Flowchart of the transformer leakage reactance selection

Current factor: $M_{C}=\frac{I_{M P P}}{I_{S C}}=0,91$

Amplitude modulation index:

$m_{\text {amax }}=1,15$ and $m_{\text {amin }} \approx 0,9$

Transformer ratio: $m=0,106$

Frequency modulation index: $m_{f}=528$

Amplitude of the total harmonic currents: Two cases are distinguished: case 1:

$\left(m_{\text {amax }}, V_{P V \min }\right)$, case $2:\left(m_{a \min }, V_{P V \max }\right)$

- $\quad$ Case 1: $I H_{1}=0,0008$

- Case 2: $\mathrm{IH}_{2}=0,0011$

Interval choice of the transformer leakage reactance:

- $\quad$ Case 1: $X_{\min 1}=0,31 \Omega ; X_{\max 1}=2,11 \Omega$

- $\quad$ Case 2: $X_{\min 2}=0,70 \Omega ; X_{\max 2}=2,11 \Omega$

The available transformer has a leakage reactance: 
$X_{\min }=\max \left(X_{\min 1}, X_{\min 2}\right)<X_{t r}=1,25<X_{\max }=$

$X_{\max 1}=X_{\max 2}$

So this transformer is suitable to connect the PV generatorinverter to the grid.

$C_{d c}$ capacitor: For $\left(\Delta V_{P V} / V_{P V}\right)=5 \%$ (33) gives: $C_{d c} \geq 61 \mu \mathrm{F}$ a normalized value is taken: $C_{d c}=63 \mu \mathrm{F}$

Voltage controller parameters: For $\tau=0,5 m s$ (19) gives: $k_{p} \approx 0$ and $k_{i}=14,58$

\section{SIMULATION RESULTS}

To validate the design and performance of the proposed PV system, simulations are performed in Matlab/Simulink environment. Two cases are considered. The climatic conditions of the first case are $1.12 \mathrm{Kw} / \mathrm{m} 2$ (illumination) and $35^{\circ} \mathrm{C}$ and those of the second case are $0.12 \mathrm{Kw} / \mathrm{m} 2$ and $15^{\circ} \mathrm{C}$. The figures 10 and 11 show the different powers of the system and the injected current.

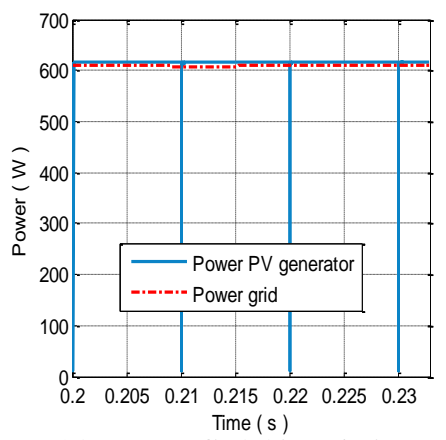

a) 1 st case : $\mathrm{G}=1.12 \mathrm{Kw} / \mathrm{m} 2$,

$\mathrm{T}=35^{\circ} \mathrm{C}$

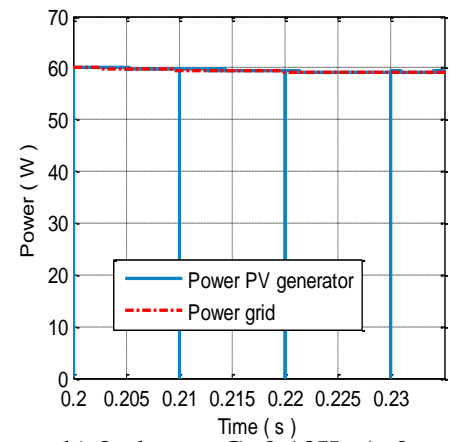

b) 2 nd case: $\mathrm{G}=0.12 \mathrm{Kw} / \mathrm{m} 2$

$\mathrm{T}=15^{\circ} \mathrm{C}$
Fig 10: Power delivered by the $\mathrm{PV}$ generator and power injected into the grid

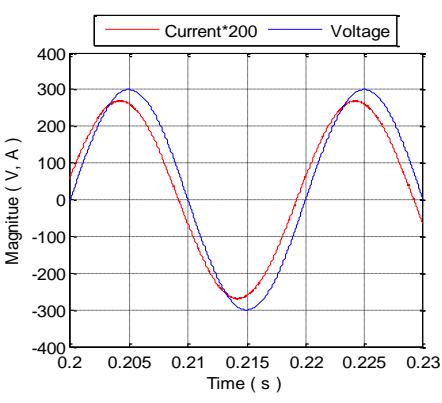

a) 1 st case : $\mathrm{G}=1.12 \mathrm{Kw} / \mathrm{m} 2$, $\mathrm{T}=35^{\circ} \mathrm{C}$

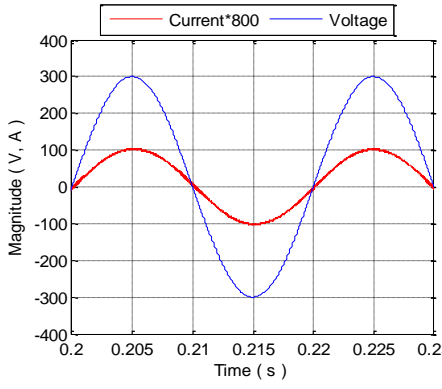

b) 2 nd case: $\mathrm{G}=0.12 \mathrm{Kw} / \mathrm{m} 2$, $\mathrm{T}=15^{\circ} \mathrm{C}$
Fig 11: Voltage and current in PCC

Table 2: shows a comparison between the theoretical and simulated results

\begin{tabular}{|c|c|c|c|c|}
\cline { 2 - 5 } \multicolumn{1}{c|}{} & \multicolumn{2}{c|}{$\begin{array}{r}\mathrm{G}=1,12 \mathrm{Kw} / \mathrm{m} 2, \\
\mathrm{~T}=35^{\circ} \mathrm{C}\end{array}$} & \multicolumn{2}{c|}{$\begin{array}{c}\mathrm{G}=0,12 \mathrm{Kw} / \mathrm{m} 2, \\
\mathrm{~T}=15^{\circ} \mathrm{C}\end{array}$} \\
\cline { 2 - 5 } \multicolumn{1}{c|}{} & Theo & Sim & Theo & Sim \\
\hline Psys $(w)$ & 618 & 608,8 & 60.2 & 59,6 \\
\hline Qr(Var) & 152,4 & 151,4 & 1,43 & 1,1 \\
\hline FPr & 0,97 & 0,9704 & 0,9997 & 0,9998 \\
\hline$m a$ & 1,008 & 1,003 & 0,985 & 1 \\
\hline THDI(\%) & 0,48 & 0,35 & 4,2 & 1,87 \\
\hline
\end{tabular}

The results summarized in tabl.2 shows a good agreement between theoretical and simulation results.

\section{CONCLUSION}

In this paper, a three phase grid-connected PV inverter with a new MPPT technique based on the determination of the P-V optimal slope of PV generator has been presented. The operating principle of the proposed MPPT technique is to adjust the phase angle between the inverter fundamental voltages and grid voltages to obtain the P-V optimal slope of the PV generator i.e. the MPP. An optimized design procedure has also been studied in this paper. Simulation results confirm the effectiveness of the proposed PV system. The proposed MPPT technique can be implemented in the PV systems with the provided design guidelines. In addition, it can further participate to the development of the PV systems. Future work will include analysis of partial shading on the proposed MPPT technique. Also experimental results will be presented.

\section{REFERENCES}

[1] World energy outlook 2013" Available on line at www.iea.org

[2] "An Assessment of Solar Energy Conversion Technologies and Research Opportunities" (PDF), Stanford University - Global Climate Change \& Energy Project. Retrieved 2 July 2008.

[3] Xiao, Weidong, Elnosh, Ammar, Khadkikar, Vinod, Zeineldin, Hatem H.; "Overview of maximum power point tracking technologies for photovoltaic power systems", IECON 2011 - 37th Annual Conference on IEEE Industrial Electronics Society, 2011 , pp: $3900-$ 3905

[4] BidyadharSubudhi, Raseswari Pradhan; "A Comparative Study on Maximum Power Point Tracking Techniques for Photovoltaic Power Systems"; Sustainable Energy, IEEE transactions on; Vol. 4, No 1; 2013, pp. 89-98

[5] Tsai-Fu Wu; Chih-Hao Chang; Li-Chiun Lin; Chia-Ling Kuo. "Power Loss Comparison of Single- and Two-Stage Grid-Connected Photovoltaic Systems", IEEE Transactions on Energy Conversion, Volume: 26 , Issue: 22011 , pp: $707-715$.

[6] Hanju Cha; Trung-Kien Vu; "Comparative analysis of low-pass output filter for single-phase grid-connected Photovoltaic inverter", Applied Power Electronics Conference and Exposition (APEC), 2010 Twenty- Fifth Annual IEEE; 2010, pp: 1659 - 1665

[7] Esram, T., Chapman, P.L., "Comparison of Photovoltaic Array Maximum Power Point Tracking Techniques", Energy Conversion, IEEE Transactions on; Volume 22; Issue $2 ; 2007 ;$ pp. 439 - 449

[8] T. Nogushi, S. Togachi, R. Nakamoto,"Short-current pulse-based maximum-power-point-tracking method for multiple photovoltaic and converter module

[9] A. Sandali, T. Oukhoya, A. Cheriti," Simple and fast Maximum Power Point Tracking for grid connected photovoltaic systems", IEEE 14th Workshop on Control and Modeling for Power Electronics (COMPEL), 2013, June 23 - 26, Salt Lake City, Utah, USA

[10] A. Sandali, T. Oukhoya, A. Cheriti," Modeling and 
Design of PV Grid Connected System Using a Modified Fractional Short-Circuit Current MPPT", IEEE 14th Workshop on Control and Modeling for Power Electronics (IRSEC), 17 - 19 October 2014, Ouarzazate, Maroc

[11] N. Mohan, T. M. Undeland, W. P. Robbins, "Power
Electronics Converters, Applications and Design", 3th ed, John Wiley \& sons

[12] H. Rashid, "Power Electronics Handbook", 3th edition.

[13] Dash, P.P, Kazerani, M, "Dynamic Modeling and Performance Analysis of a Grid-Connected CurrentSource Inverter-Based Photovoltaic System" 